\title{
Moldy buildings, health of their occupantsand fungal prevention
}

\author{
Mihinova $\mathrm{D}^{1}$, Pieckova $\mathrm{E}^{2}$ \\ Department of Health Protection, Faculty of Public Health, Slovak Medical University, Bratislava, Slovakia. \\ daniela.mihinova@szu.sk
}

\begin{abstract}
Microscopic fungi are important biological pollutants in the indoor environment, they are spread generally: on building materials, carpets, ceiling tiles, insulations, any surfaces, wallpapers, or in heating, ventilation, and air conditioning systems. Molds are able to grow on any materials, as long as moisture and oxygen are available. Exposure to fungi in indoor environments (esp. in water-damaged buildings) can cause adverse health effects, such as allergy, asthma, hypersensitivity pneumonia, mucous membrane irritation, different toxic effects, or even mycoses (in immunocompromised individuals) - alone or in combination. As serious adverse health effects could be caused antifungal prevention is an absolute need.

This review article summarizes the occurence of fungi in the indoor environment of buildings and their contribution to occupants' health problems, and preventive measures against molds (Tab. 1, Fig. 1, Ref. 48). Full Text in PDF www.elis.sk.

Key words: microscopic fungi, indoor environment of buildings, primary causes of fungal occurence, system of fungal prevention.
\end{abstract}

It si absolutely clear that poor quality of indoor environment in buildings can contribute to lots of health troubles. The importance of its evaluation is permanently growing. The problem of indoor environment quality is one of the most relevant public health tasks (1).

The long-lasting interest of medical authorities and technical specialists as well paid to quality of indoor environment deals with the fact that modern people spend predominant part of life in closed spaces (2).

Nowadays the modern society is exposed to many risk factors, which include various chemical substances in living and working environment. The toxic (and even carcinogenic) effects of these substances can threaten human health significantly. Besides industrial substances, some others toxic natural compounds were found to have adverse effects on the human health. These factors include toxic fungi and mycotoxins in foods and also in living and working environment. (3).

Microorganisms belong to important biological pollutants in the indoor environment (4). Toxic exposure to molds and mycotoxins in public buildings, offices, and homes is really common (5).

\section{Exposure to microscopic fungi and mycotoxins in indoor en- vironment}

Some epidemiological studies of damp buildings have focused on health risks from indoor exposure to toxic fungi and mycotoxins

${ }^{1}$ The Department of Health Protection, Faculty of Public Health, Slovak Medical University, Bratislava, Slovakia, and ${ }^{2}$ The Department of Microbiology, Research Base, Slovak Medical University, Bratislava, Slovakia Address for correspondence: D. Mihinova,RND, Dept. of Health Protection, SZU, Limbova 12, SK-83303 Bratislava, Slovakia
(6-8). Most of these studies have not considered assessment of such hazards in the outdoor environments (8). In Taiwan, the study began by evaluating the airborne fungal concentrations at urban and suburban areas of the city in two seasons. The geometric mean concentration for indoors was 8,946 CFU (colony forming units)/ $\mathrm{m}^{3}$ in winter and 4,381 in summer, for outdoors, it was 11,464 $\mathrm{CFU} / \mathrm{m}^{3}$ in winter and 4,689 in summer. In summer, the total fungal concentrations, both indoors and outdoors, of suburban homes were significantly higher then those of urban homes (9). O'Connor et al (10) performed a home environmental survey and measured the concentrations of culturable airborne fungi inside and outside the homes of 414 mold-sensitive children with asthma in 7 urban communities. The airborne fungi encountered indoors qaulitatively generally paralleled those found outdoors. Indoor fungal concentrations were correlated with outdoor concentrations measured in the same study. The indoor concentration was an indicator of the relative moldiness of a home. The concentration of fungi in indoor air exceeded the outdoor one. The indoor-outdoor difference was significantly related to home characteristics, including dampness, having a cat and cockroach infestation.

Many studies proved isolation of Stachybotrys sp. (11-13) and other genera, incl. Aspergillus, Penicillium, Cladosporium, Chaetomium, Ulocladium and Alternaria (13-17) from the indoor environment of buildings. Scheel et al. (18) collected samples of the moldy ceiling tiles at he Central Middle School in Tennessee, USA. Stachybotrys spores were evident on their majority. Oher fungal contaminants identified included the xerophilic species of the genera Aspergillus and Penicillium, both of which are known respiratory allergens that might produce mycotoxins. Ulocladium sp., a hydrophile that grows on cellulose material, was also identified. In the United Kingdom, Hunter et al (19) used air filtration to 
monitor 163 homes for the presence of fungi and bacteria over the period of November 1990 to December 1992. The geometric mean count was $234 \mathrm{CFU} / \mathrm{m}^{3}$ air for fungi. In a more intensive study of 35 of the houses, mean counts were 912 and $818 \mathrm{CFU} / \mathrm{m}^{3}$ air for fungi in living rooms and beedrooms. Penicillium spp. was the most frequently isolated fungus, found in $53 \%$ of samples. It was followed by Cladosporium and Aspergillus. In Norway, Dotterud et al (20) found that Penicillium was the most common mold in homes and schools, followed by Aspergillus, Cladosporium, and Mucor.

Mold growth within homes and other buildings has been associated with varying degrees of human health problems (21). Exposure to fungi, particularly in indoor environments (in water-damaged buildings) can cause adverse health effects, such as mycoses (in immunocompromised individuals), allergy, asthma, hypersensitivity pneumonia, mucous membrane irritation, and toxic reactions - alone or in combination (21-26). Building-related illnesses due to mycotoxins have not been fully proven in the literature yet $(22,23)$.

Molds are common and important allergens. About $5 \%$ of individuals are predicted to have some allergic airway symptoms from molds over their life-time (27). In the UK, Potter et al. (28) detected allergic responses to 9 different fungal allergens in a survey of 2,000 patients with allergic respiratory diseases. Also in Sweden, Wickman et al (29) found that Penicillium, Alternaria, and Cladosporium molds were more common in homes of children with allergies, and Neas et al (30) reported that morning lung malfunction was inversely associated with Epicoccum and Cladosporium spore concentrations amongst a panel of 108 children. Jussila et al (31) isolated spores of Aspergillus versicolor in moisture-damaged buildings. These spores caused dose and time dependent acute inflammation in mouse lungs. Cytotoxicity was marked only at the highest spore dose.

Allergens dispersed by airborne fungal spores play an important but poorly understood role in the underlying cause and exacerbation of asthma. Previous studies suggest that spores of Alternaria and Aspergillus release greater quantities of allergen after germination than before it. It is unknown whether this is true of other allergenic fungi. For 9 of 11 species (Alternaria alternata, Cladosporium herbarum, Aspergillus fumigatus, Botrytis cinerea, Epicoccum nigrum, Exserohilum rostratum, Penicillium chrysogenum, Stemphylium botryosum, Curvularia lunata, Trichoderma viride, Bipolaris spicifera), between $5.7 \%$ and $92 \%$ of spores released allergen before germination. Spores of other Penicillium and Trichoderma did not release detectable allergens. After germination, all spores that germinated had allergen elution from their hyphae. Eight of 11 species showed a significant increase $(\mathrm{p}<0.05)$ in the percentage of spores eluting detectable allergen (32). Based on the results of the meta-analyses, building dampness and mold are associated with approximately $30-50 \%$ increase in a variety of respiratory and asthma-related health outcomes (33).

Rea et al (5) studied 100 patients who had been exposed to toxic molds in their homes. The predominant molds identified were Alternaria sp., Cladosporium sp., Aspergillus sp., Penicillium sp., Strachybotrys sp., Curvularia sp., Basidiomycota, Myxomycota, Epicoccus sp., Fusarium sp., Bipolaris sp. a Rhizopus sp. The pre- dominant signs and symptoms observed in the subjects were as follows: respiratory symptoms (sneezing, rhinorrhea, nasal stuffiness, dyspnoe and wheezing) in 64 patients, neurological symptoms (short-term memory loss, imbalance and dizziness) in 70 patients, immunological symptoms (hypersensitivity to molds, foods and chemicals) in 100 patients, gastrointestinal symptoms (bloating, gas and cramps) in 24 patients, musculoskeletal symptoms (muscle and joint aches and tenderness) in 29 patients and cardiovascular symptoms (bruising, hemoptysis, and petechiae) in 10 patients.

A majority of occupants of a newly renoved historic courthouse in Calgary, Alberta, Canada, reported multiple (3 or more) health-related symptoms, and several reported more than 10 persistent ones. Most required at least a day out of the building to recover from their problems. There were identified molds that produce mycotoxins in the building, such as Stachybotrys chartarum and Emericella nidulans, along with fungal organisms of the genera Aspergillus, Penicillium, Cladosporium, Chaetomium, Rhizopus/Mucor, Alternaria, Ulocladium and Basidiomycota. Renovations of this historic building failed to provide adequate thermal and vapour barriers, thus allowing most indoor air to migrate into the building closure, causing condensation. Mold grew on the condensation and was dispersed through the courthouse, includingthe furniture and files. The courthouse was closed and a few facilities were modified with low-offgassing materials, better ventilation and air filtration, and strict building maintenance to accommodate those occupants of the older building who had developed multiple chemical sensitivities (34). On the different plasters, mixtures of the spores of Aspergillus ustus, A. versicolor, Cladosporium sphaerospermum and Penicillium spp. held their vitality from $40 \mathrm{~d}$ to 3 months, i. e. up to the end of the experiment $(35,36)$.

In the United Kingdom, Platt et al (37) examined the relationship between fungal spore counts and self-reported symptoms amongst the occupants of almost 600 homes. They were associated with an elevated prevalence of reported wheeze and fever in children, and high blood pressure, and breathlessness in adults.

Gray et al (38) in their study investigated multiple health difficulties following the exposure to various molds in 209 persons in water-damaged buildings. The authors concluded that exposure to mixed molds and their associated toxins had lead to multiple health problems involving the central nervous and the immune systems, in addition to pulmonary difficulties and allergies. Mold exposure also initiates inflammatory processes. The authors propose the term „mixed mold mycotoxicosis“ for the multisystem illness observed in these persons.

Until now, the ciliostatic activity of sterigmatocystin ,in vitro“ has been proven, that is the carcinogenic mycotoxin produced by A. versicolor and Chaetomium spp., even it belonged to the most active fungal secondary metabolites tested $(39,40)$. Kelman et al (41) tried to model a maximum possible dose of mycotoxins that could be inhaled in 24 hrs of continuous exposure to a high concenrtation of aflatoxins B1 and B2, satratoxins $\mathrm{G}$ and $\mathrm{H}$, fumitremorgens B and C, verruculogen, and trichoverrols A and B. These calculated doses are compared to effects' data for the same mycotoxins. None of the maximum doses modelled were sufficiently high to cause any adverse effect. 


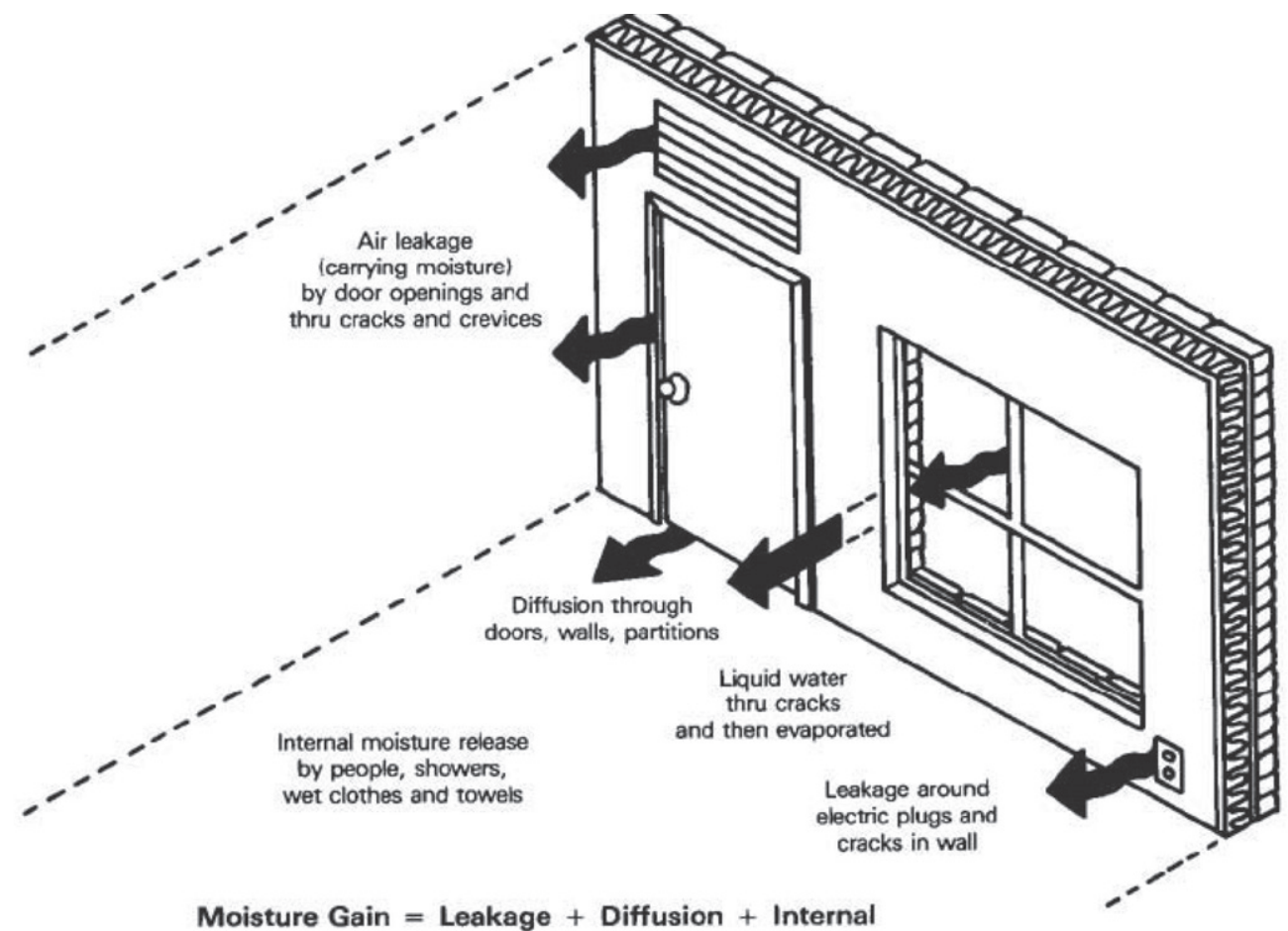

Fig. 1. Moisture gain in buildings (42).

\section{Conditions enabling the growth of indoor microscopic fungi}

Molds are found almost everywhere in our environment, both outdoors and indoors. They can grow on just about any substances, as long as moisture and oxygen are available. Mold growth may occour when excessive moisture accumulates in building or on building materials, including carpets, ceiling tiles, insulation, paper, wallboard, wood, surfaces behind wallpaper, or in heating, ventilation, and air conditioning systems (HVAC). It is impossible to eliminate all molds and mold spores in the indoor environment. However, moisture control is the most important strategy for reducing indoor mold growth $(42,43)$.

Water enters buildings both as a liquid and as a gas (water vapour). Water, in its liquid form, is introduced intentionally in bathrooms, kitchens, and laundries and accidentally by way of leaks and spills. Some of that water evaporates and joins the water vapor that is exhaled by building occupants as they breathe or that is introduced by humidifiers. Water vapour also moves in and out of the building as part of the air that is mechanically introduced or that infiltrates and exfiltrates through openings in the building shell. A lesser amount of water vapour diffuses into and out of the building through the building materials themselves. Figure 1 illustrates locations of moisture entry (42).

The dampness of substrate is one of the basic conditions of mold's life. Their optimal water activity in substrate ranges between 0.60 and 0.99 and their optimal relative humidity of air fluctuates between 80 and $100 \%$.
Other significant parameter related to humidity of building materials is the dew point temperature. The condensation of water vapour appears due to cooler air around the material surface that is below the temperature of dew point. Dew points - actually, critical temperature to develop mold growth - on inner wall surfaces under different thermal and humidity conditions in an appartment in Bratislava, Slovakia, are illustrated in Table 1 (44).

The building materials under given atmospherical conditions contain certain amounts of so-called steady moisture, which is absorbed from surrounding air. The quantity of this absorbed humidity is dependent on temperature, relative humidity, porosity of material and contents of hygroscopic salts. The building material becomes the source of humidity, when its humidity is higher than steady moisture. In this instance, moisture of building can be high even at low relative humidity of the air.

The main sources of moisture in buildings are:

- capillary action of moisture - imperfections in hydroisolation of building subsoil and inadequate reduction of moisture causing wetness on construction of building subsoil;;

- raining in building - in roof constructions and through breaches in circumferentid walls consisting of pieces;

- leaking in sanitary installations - at uncaulking joints of sanitarity distribution system, banged up outlet baths, washbasin and kitchen sink;

- condensation of water on internal surfaces of construction - in 
Tab. 1. Dew points on inner wall surfaces in a flat (44).

\begin{tabular}{cccc}
\hline $\begin{array}{c}\text { Air } \\
\text { temperature } \\
\left({ }^{\circ} \mathrm{C}\right)\end{array}$ & $\begin{array}{c}\text { Relative } \\
\text { humidity } \\
(\%)\end{array}$ & $\begin{array}{c}\text { Relative humidity } \\
\text { calculated for } 20^{\circ} \mathrm{C}, \\
\text { atmospheric pressure } \\
2336.7 \mathrm{~Pa}(\%)\end{array}$ & $\begin{array}{c}\text { Dew point } \\
\text { calculated for } \\
\text { relative humidity } \\
80 \%\left({ }^{\circ} \mathrm{C}\right)\end{array}$ \\
\hline 18 & 50 & 44.1 & 10.74 \\
19 & 50 & 47.0 & 11.68 \\
20 & 50 & 50.0 & 12.62 \\
21 & 50 & 53.2 & 13.57 \\
22 & 50 & 56.5 & 14.51 \\
23 & 50 & 60.1 & 15.45 \\
24 & 50 & 63.8 & 16.40 \\
25 & 50 & 67.7 & 17.34 \\
\hline
\end{tabular}

places with lower surface temperature under temperature of dew point;

- activities of occupants of buildings - an excessive amount of flowers, aquariums, vaporizes, washing and airing laundry, cooking, and an exsessively sealed windows.

The molds can not exist without occurence of appropriate breeding ground - substrate. Primary nutrients included are organic compounds couting carbon and nitrogen (proteins and saccharides) and minerals for occurence of hint of organic compounds. The most convenient environment for life of molds is the acidic one. The optimal $\mathrm{pH}$ value ranges between 5 and 7 in dependence on their species. The molds need oxygen, possibly carbon dioxide, but they do not need light (3).

System of mold and mycotoxin prevention in living and working environment

There is a high need to control moisture in both new and existing constructions because of the significant health consequences that can result from dampness and mold. Dampness and mold in buildings is undoubtly a significant public health problem with substantial economic impact (45).

Preventive measures against molds consist of:

- assignement of suitable air circulation by periodical ventilation (ventilation system, exchange air by oppening windows),

- reparations, adjustments, constructions of spaces and buildings to eliminate all sources of humidity,

- periodical building maintenance,

- employment of suitable impermeable materials for flooring,

- adjustment of climate conditions of building by right regulation of fumigation and humidity (relative humidity maintain below $60 \%$, ideally $30-50 \%$, if possible),

- adjustment of right function of vaporizer in kitchen, regular defrosting, washing and disinfection of refrigerator and freezer,

- performance of periodical cleaning of spaces (use suitable cleaners and disinfectants, regular disposal of waste),

- respect to the right principles of storage of materials (e. g. not to store objects directly at the walls),

- performance of periodical control of occurrence of molds (3, 42, 43, 46, 47).

\section{Conclusion}

Up to recently, the direct and indirect relationship between presence of microscopic fungi in buildings and health status of their occupants has not been exactly proven. Monitoring of exposure to fungi in the indoor environment is complicated, due to the absence of standardized practical methods to evaluate relations among the indoor microclimate in buildings, their outdoor environment and microscopic fungi $(39,40,48)$. This problem requires strong attention not only in public health, but needs an integrated approach through the large spectrum of sciences.

\section{References}

1. Slotová K. Sick building syndrome. Enviromagazine 2006; 2: 12-15.

2. Ševčíková L et al. Hygiene. Bratislava; Comenius University, 2006, $328 \mathrm{p}$.

3. Malír F, Ostrý V et al. Filamentous fungi (mold), mycotoxins and human health. Brno: National Center of Nursing and Non-Medical Health Care Disciplines; 2003: 349.

4. Jones AP. Indoor air quality and health. Atmospheric Environment 1999; 33: 4535-4536.

5. Rea WJ, Didriksen N, Simon TR., Pan Q, Fenyves EJ, Griffiths B. Effect of toxic exposure to molds and mycotoxins in building-related illnesses. Arch Environ Health 2003; 58 (7): 399-405.

6. Jarvis BB, Miller JD. Mycotoxins as harmful indoor air contaminants. In: Appl Microbiol Biotechnol 2005; 66 (4): 367-372.

7. Kuhn DM, Ghannoum MA. Indoor mold, toxigenic fungi, and Stachybotrys chartarum: Infectious disease perspective. Clin Microbiol Rev 2003; 16 (1): 144-172.

8. Sudakin D, Fallah P. Toxigenic fungi a mycotoxins in outdoor, recreational environments. Clin Toxicol (Phila) 2008; 46 (8):738-744.

9. Pei-Chih W, Huey-Jen S, Chia-Yin L. Characteristics of indoor and outdoor airborne fungi at suburban and Urban homes in two seasons. Sci Total Environ 2000; 253 (1-3): 111-118.

10. O'Connor GT, Walter M, Mitchell H, Kattan M, Morgan WJ, Grichalla RS, Pongracic JA et al. Airoborne fungi in the homes of children with astma in low-income urban communities: The Inner-City Asthma Study. J Allergy Clin Immunol 2004; 114 (3): 599-606.

11. Andersen B, Nielsen KF, Jarvis SB. Characterisation of morphologically, chemically and physiologically different Stachybotrys species from water-damaged buildings. Mycologia 2002; 94: 392-403.

12. Barnes C, Bucklay S, Pacheco F, Portoy J. IgE-reactive proteins from Stachybotrys chartarum. Ann Allergy, Asthma, \& Immun 2002; 89: 29-33.

13. Gravesen S, Nielsen PA, Iversen R, Nielsen KF. Microfungal conatmination od damp buildings - examples of risk constructions and risk materials. Environ Health Persp 1999; 107 (3): 505-508.

14. Chew GL, Rogers HA, Burge ML, Muilenberg, DR. Gold, Dustborne annd airborne fungal propagules represent a different spectrun of funi with deffering relations to home characteristics. Allergy 2003; 58: 13-20.

15. Engelhart S, Loock A, Skutlarek D, Sagunski H, Lommel A, Färber H, Exner M. Occurence of toxigenic Aspergillus versicolor isolated and sterifmatocystin in carpet dust from damp indoor environments. Apll Environ Microbiol 2002; 68: 3886-3890. 
16. Martinez Ordaz VA, Rincon-Castaneda CB, Esquivel Lopez G, Lazo-Saenz JG, Lorenz Meraz MT, Velasco Rodrigeuez VM. Fungal spores in the environment of the asthametic patient in a semi-desert area of Mexico. Rev Alerg Mex 2002; 49: 2-7.

17. Shelton BG, Kirkland KH, Flanders WD, Morris GK. Profiles of airborne fungi in buildings and outdoor environments in the United States. Appl Environ Microbiol 2002; 68: 1743-1753.

18. Scheel HM, Rosing WC, Farone AL. Possible sources of sick building syndrome in a Tennessee Middle School. Arch Environ Health 2001; 56(5): 413-417.

19. Hunter CA, Hull AV, Higham DF, Grimes CP, Lea RG. Fungi and bacteria. In: Berry RW, Brown VM, Coward SKD et al (Eds). Indoor air quality in homes, the building research establishment indoor environment study, part 1. Construction Research Communications, London; 1996.

20. Dotterund LK, Vorland LH, Falk ES. Viable fungi in indoor air in homes and schools in the Sor-Varanger community during winter. Paediatric Allergy and Immunology 1995; 6 (4): 181-186.

21. McGinnis MR. Pathogenesis of indoor fungal diseases. Med Mycol 2004; 42 (2): 107-117.

22. Bardana EJ Jr. Indoor air quality and health does fungal contanination paly a significant role? Immunol Allergy Clin North Am 2003; 23 (2): 291-309.

23. Chapman JA, Terr AI, Jacobs RL, Charlesworth EN, Bardana EJ Jr. Toxic mold: phantom risk vs science. Ann Allergy Asthma Immunol 2003; 91 (3): 222-232.

24. Green BJ, Tovey ER, Sercombe JK, Blachere FM, Beezhold DH, Schmechel D. Airborne fungal fragments and allergenicity. Med Mycol 2006; 44 (1): S245-255.

25. Vojdani A, Campbell AW, Kashanian A, Vojdani E. Antibodies against molds and mycotoxins following exposure to toxigenic fungi in a water-damaged building. Arch Environ Health 2003; 58 (6): 324-336.

26. Terr AI. Are indoor molds casusing a new diseases? J Allergy Clin Immunol 2004; 113 (2): 221-226.

27. Hardin BD, Kelman BJ, Saxon A. Adverse human health effects associated with molds in the indoor environmnet. J Occup Environ Med 2003; 45 (5): 470-478.

28. Potter PC, Juritz J, Littlle F, McCaldin M, Dowdle EB. Clustering of fungal-allergen specific IgE antibody responses in allergic subjects. Annals of Allergy 1991; 66 (2): 149-153.

29. Wickman M, Gravesen S, Nordvall SL, Pershagen G, Sundell J. Indoor viable dust-bound microfungi in relation to residential characteristics, living habitats, and symptoms in atopic and control children. J Allergy Clin Immunol 1992; 89 (3): 752-759.

30. Neas LM, Dockery DW, Burge H, Koutrakis P, Speizer FE. Fungus spores, air pollutants, and other determinants of peak expiratory row rate in children. Amer. J Epidemiology 1996; 143 (8): 797-807.
31. Jussila J, Komulainem H, Kosma VM, Nevalainen A, Pelkonen J, Hirvonen MR. Spores of Aspergillus versicolor isolated from indoor air of a moisture-damaged building provoke acute inflammaion in moiúse lungs. Inhalation Toxicology 2002; 14: 1261-1277.

32. Green BJ, Mitakakis TZ, Tovey ER. Allergen detection from 11 fungal species before and after germination. J Allergy Clin Immunol 2003; 111 (2): 285-289.

33. Fisk WJ, Lei-Gomez Q, Mendell MJ. Meta-analyses of the associations of respiratory health effects with dampness and mold in homes. Indoor Air 2007; 17 (4): 284-296.

34. Lee TG. Health symptoms caused by molds in a courthouse. Arch Environ Health 2003; 58 (7): 442-446.

35. Piecková E, Jesenská Z. Study of mold-contaminated wall plaster on in vitro. Hygiene 2000; 45: 37-41.

36. Pivovarová Z, Piecková E, Sternová Z, Droba E. Antifungal properties of building materials. Healthy buildings 2006 - Abstract. Lisbon, Portugal 2006; 60.

37. Platt SD, Martin CJ, Hunt SM, Lewis CW. Damp housing, mould growth, and symptomatic health state. British Medical Journal 1989; 298 : 1673-1678.

38. Gray MR, Thrasher JD, Crago R, Madison RA, Arnold L, Campbell AW, Vojdani A. Mixed mold mycotoxicosis: Imunological changes in humans following exposure in water-damaged buildings. Arch Environ Health 2003; 58 (7): 410-420.

39. Jesenská Z, Bernát D. Effects of mycotoxins on in vitro movement of tracheal cilia from one-day-old chicks. Folia Microbiol 1994; 39: 155-158.

40. Piecková E. In vitro toxicity of indoor Chaetomium Kunze ex Fr. Ann Environ Med 2003; 10: 9-14.

41. Kelman BJ, Robbins CA, Swenson LJ, Hardin BD. Risk from inhaled mycotoxins in indoor office and residential environmnets. Int J Toxicol 2004; 23: 3-10.

\section{2. http://www.epa.gov/mold/pdfs/moldremediation.pdf}

43. http://www.osha.gov/Publications/preventing_mold.pdf

44. Piecková E, Pivovarová Z. Determination of antifungal properties of building materials used in model experiments. In: Sternová, Z.: Effect of building matrials and constructions on quality of life. Final report of the State program of research and development task P-17/2004. Bratislava, 2005; p. 1-45.

45. Mudarri D, Fisk WJ. Public health and economic impact of dampness and mold. Indoor Air 2007; 17 (3): 226-235.

46. http://www.epa.gov/mold/pdfs/moldguide.pdf

47. Warsco K, Lindsey PF. Proactive approaches for mold-free interior environmnets. Arch Environ Health 2003; 58 (8): 512-522.

48. Piecková E, Wilkins K. Airway toxicity of house dust and its fungal composition. Ann Agric Environ. Med. 2004; 11: 67-73. 